\title{
Remanufacturing and Benefits Analysis of Construction Machinery Hydraulic Valves
}

\author{
Dong $\mathrm{Xu}^{1, \mathrm{a}}$, Jie Zhang ${ }^{2}$ \\ ${ }^{1,2}$ Nanchang Institute of Science and Technology, 330108 \\ axudongjx@126.com
}

Keywords: Machinery remanufacturing; Hydraulic valves; Benefits

\begin{abstract}
It is known that China is a country with rich natural resources and vast territory. Even though, the resource stock is declining in the growing process of every industry. Focusing on current resource lackage situation, recycling on resources attracts more attention from the public. Reproducing is one of the recycling measures demanding highly in techniques. This needs to be mentioned especially in machinery production industry because of the benefits it can bring upon the original productions and less damage to the original machines. This paper focuses on the remanufacturing of construction machinery hydraulic valves and its benefit.

Remanufacturing construction machinery is an indispensable in the manufacture way of engineering machinery manufacturing, the remanufacturing of hydraulic valve is one of the important. In general, the working environment is very bad, such as soil dust, cold heat, various difficulties and hardships which caused serious influence on the engineering machinery service life, leading a large number of hydraulic valve failure every year. The related enterprises remanufacture batch of useful spares by recycling of waste hydraulic valves. By satisfying the demand, remanufacturing greatly reduces the cost of production, saving resources, and gains huge economic benefits.
\end{abstract}

\section{Failure Mode of Hydraulic Valves}

First, abrasion. The failure caused by the wear of the hydraulic parts is more common. Parts in the working process produce mutual friction forces leading the surface changes and the quality of the parts diminishes not enough to perform. There are many reasons explaining the friction existing such as rubbish and oxidized materials from oil in the hydraulic valves resulting corruption and abrasion on the surface then producing impurities intensify the friction force between the hydraulic valves. Fig 1 shows the inner abrasion situation of a hydraulic valve.
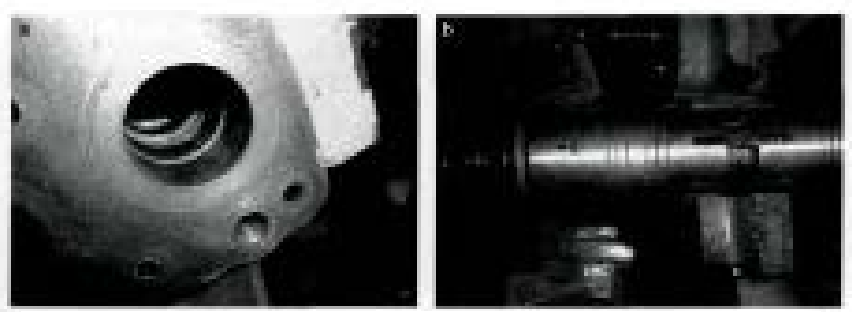

Fig 1 abrasion situation inside a hydraulic valve

Second, deformation of a hydraulic valve. When the hydraulic valve suffers an excessive force outside, it will deform and lower the flexibility of its spares which produces unstable inner pressure finally affects the mutual transform inside hydraulic valves.

Third, overwork of a hydraulic valve. Under a long-term, high load working condition, the hydraulic spool, valve seat, spring will have to suffer from the overwork and crack, makes the spring elasticity decreased, length changes, the valve seat damaged, which will directly affect the normal work of the hydraulic valve. 
Fourthly, corrosion of some acid substances inside the hydraulic valves. The hydraulic oil may be mixed with some water or some acid materials which accumulate by time resulting to surface corrosion, so as to its accuracy and sealing effect, and thus leading to failure.

\section{Remanufacturing Process}

First, disassemble the hydraulic valve. This process is the basic step of the remanufacturing of hydraulic valves. In this step, start to clean it, remove the surface paint and make preliminary judgment of whether it can be remanufactured. If not, we can just throw away. In the process of dismantling, it is necessary to ensure the integrity of the hydraulic valve not causing a second damage.

Second, conduct ultrasonic cleaning on disassembled qualified hydraulic valves. The dirt attached to the parts can be cleaned effectively by ultrasonic vibration and stirring. For its own deep-seated oil, it can be dissolved in its similar solvent, which can apply the brush to clean without affecting the surface.

Third, close examination is needed after the cleaning work and spares should be sorted out in an orderly way for better use. Carefully detect whether there is residual foreign body, whether smooth, whether the surface has wear and tear and whether there is deformation.

Fourth, the size repair method is used to conduct repair and replacement. Through the mechanical removal of uneven wear surface, we can get a new size data. Repair or replace the relevant matching parts by this data. In this step, honing process is employed which can save materials and fully restore hydraulic valves.

Fifth, remanufacture performance index of flow amplifier on the new standard. Have hydraulic valve fixed on the test bench, start the test rig and use the tool to drive the stem to observe the operation flexibility of the stem. When the valve stem is in the middle position, the two oil port of the connecting cylinder is oil overflow. Operate the steering wheel to observe the maximum rotation and return pressure of the piston rod. When both of them reach zero position, the value can be defined as meeting the technical requirements. Take a note of it and notice if there is a leakage phenomenon on the articular surface. Rework defective parts.

Sixth, spray painting and packaging for its appearance. Test qualified products and remove all surface rust, dirt and other debris before paint. Take good control of the angle and speed when spraying to ensure the superficial smooth and plain. After coating, there still needs tests of thickness tester and gloss meter. At last, put the qualified products into storage.

\section{Benefits Analysis on Hydraulic Valve Remanufacturing}

First, the social benefits. Hydraulic valves in engineering machinery are organized by parts of different sizes and needs remanufacture work on the damaged parts, which means an overall remake on every part in the whole process. This involves more labors into work and offers more jobs to the unemployed. This also introduces more tax income.

Second, the economic benefits. Instead of making a new hydraulic valve, remanufacturing a worn-out one takes shorter time, spends less cost, waste less time in delivering goods, lower the prices, and most importantly, increase producer's output, which reaches a win-win situation for producers and customers. This following Fig2 shows a comparison between making a new one and reproducing the old ones. 

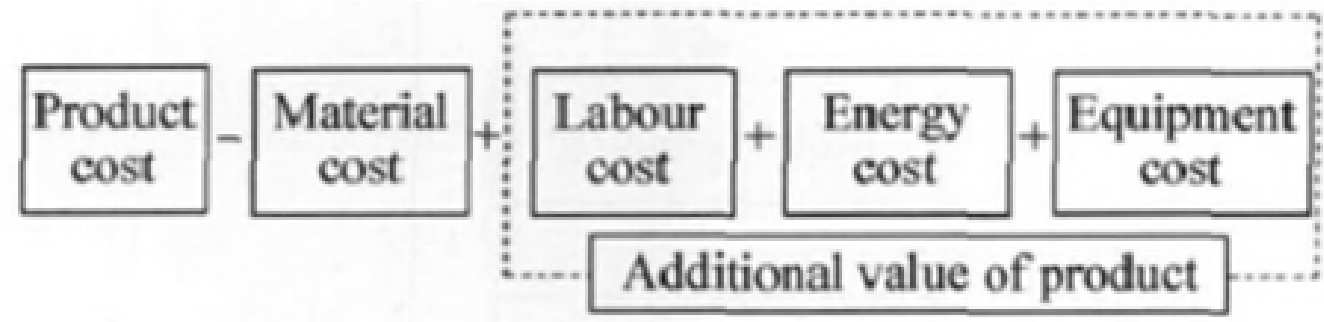

Fig 2

Third, the resource benefits. First of all, this method is an efficient way of saving resources and materials. Because remaking is the direct use of original products, new materials have been better preserved. In this way extensive and deeper exploration for a lack of resource can be avoided. More detailed information can be found in the below Table 1.

Table 1 Reuse parts

\begin{tabular}{|c|c|c|c|c|}
\hline Item & Part name & Material & Mass $/ \mathrm{kg}$ & Reuse rate/\% \\
\hline 1 & Cover & HT250 & 3 & 95 \\
\hline 2 & Valve seat & $40 \mathrm{Cr}$ & 0.3 & 90 \\
\hline 3 & Sleeve & HT200 & 2 & 90 \\
\hline 4 & Spring holder & 35 & 0.5 & 95 \\
\hline
\end{tabular}

Results from previous researches can be found out that the available value of parts takes $7 \%$ in the total value, parts which needs change takes $3 \%$ while parts that can be reproduced takes $90 \%$ of the whole. Each year amplifier valve and distribution valve output through remanufacturing reaches 2000, saving $90 \%$. There consumes about $85 \%$ fire, water and electricity in 70 ton engineering materials. More details are shown in Table 2.

Table 2 Remanufacturing parts

\begin{tabular}{|c|c|c|c|c|c|}
\hline Item & Part name & Material & Mass $/ \mathrm{kg}$ & Failure & Reman rate/\% \\
\hline 1 & Valve body & HT250 & 45 & Hole wear & 95 \\
\hline 2 & Spool & $20 \mathrm{CrMnTi}$ & 2 & Surface wear & 95 \\
\hline 3 & Tilt spool & $40 \mathrm{Cr}$ & 2 & Surface wear & 95 \\
\hline 4 & Lift spool & $40 \mathrm{Cr}$ & 2 & Surface wear & 95 \\
\hline
\end{tabular}

Fourth, not only an ample amount of resource have been wasted in the new product processing, but also a damaging pollution comes along. In the mining phase, blasting dust, chemicals and other ways have caused serious damage to the environment like waste water, waste gas and other industrial waste. Some enterprises ignore the laws and regulations of the country vastly produce industrial waste and wanton emissions, causing a non-recoverable damage to rivers, forest and the whole ecological climate. On the contrary, the remanufacturing can significantly reduce the adverse effects of resource consumption, thereby reducing the generation of harmful substances. From the environment protection vision, the enforcement of remanufacturing is a positive contribution.

\section{Conclusion}

This paper describes the failure mode in hydraulic valves remanufacturing and various benefits it may bring about. The first thing we learned is the fragileness of hydraulic valves. With poor 
performance of it, big loss can be produced in the engineering process. Thus it calls for a timely change of hydraulic valves, which can be satisfied with remanufacturing work of hydraulic valves. Besides, the remaking can better save the resource, protect the environment and offer more jobs to the unemployed. Therefore, it is necessary to support the contribution of machinery manufacturing enterprises to the sustainable development of China.

\section{Reference}

[1] Wei Huang, Jun Yang, Qi Hong, Daixiang Wei, Guiwei Xu, Hui Wu. Remanufacturing and Benefits Analysis of Construction Machinery Hydraulic Valves [J]. China Surface Engineering, 2013, 02:107-111;

[2] Can Wang, Xuemei Zong, Bing He. Remanufacturing and Benefits Analysis of Construction Machinery Hydraulic Cylinders [J]. Construction Machinery and Equipment, 2013, 06:45-48+204;

[3] Tianxiao Zhang. Reliability Sensitivity Analysis and Reliability Design of Hydraulic Components [D]. Jilin University, 2014;

[4] Chanyi Han. The Fundamental Study on Energy-saving Methods of Hydraulic System [D]. Northeastern University, 2010. 